\title{
$R_{\text {evista }} \mathrm{EaD} \&$
}

tecnologias digitais na educação

\section{A vitória do controle: reflexões de uma ex- perimentação que não aconteceu}

\author{
Albio Fabian Melchioretto, FURB \\ albio.melchioretto@gmail.com \\ FILOMENA MARIA G.S.C. MOITA \\ filomena_moita@hotmail.com
}

Resumo: A presente reflexão é fruto de uma parte da pesquisa de dissertação $e$ buscará refletir a primeira tentativa de vivenciar a aplicação de uma aula de filosofia com uso de redes sociais virtuais em uma escola da rede pública do Estado de Santa Catarina, Brasil. A problemática que envolve a pesquisa é uma análise dos fatos, a partir de uma leitura de Gilles Deleuze e Félix Guattari, a partir da apresentação das características aproximativas do rizoma. Os fatos consentem na análise dos mecanismos de controle que impediram a realização da atividade com os sujeitos previstos. A pesquisa tem por objetivo refletir o exercício de mecanismos de controle que atuam sobre a escola e os escolares. $A$ reflexão é guiada por uma leitura dos pensadores franceses, onde o rizoma é tomado como método guia para a experimentação e para a análise dos resultados. $O$ instrumento de coleta da pesquisa foi a construção de um diário de bordo.

Palavras-chave: educação, redes sociais, rizoma, filosofia.

Abstract: This reflection is the result of part of the dissertation research and will seek to reflect the first attempt to experience the application of a philosophy class using virtual social networks in a public school in the state of Santa Catarina, Brazil. The problem involving the research is an analysis of the facts, from a reading of Gilles Deleuze and Félix Guattari, from the presentation of the approximate characteristics of the Rhizome. The facts allow the analysis of mechanisms of control that prevented the realization of the activity with the subject. The research aims to reflect the exercise of control mechanisms that Act on the school and students. The reflection is guided by a reading of the French thinkers, where Rhizome is taken as a guide to experimentation and to the 
analysis of the results. The collection of the research instrument was the construction of a logbook.

Keywords: education, social networks, rhizome, philosophy.

\section{Introdução}

O que apresento neste texto é uma reflexão que nasce como parte da primeira tentativa de experimentação que propus para a realização da dissertação em Educação. Nela apontei linhas, direções, fugas e outras conexões nascidas, não como certezas, nem como setas de caminho, mas como possibilidade de não encontrar resposta, nem uma explicação, mas possibilitar novas conexões e novas oportunidades. Um texto que, antes de qualquer coisa, representa uma ruptura e vontade de tecer novos mapas, a fim de continuar a caminhar, porém, com menos setas, com menos verdades e com mais dúvidas. O tema que motiva este estudo é o uso das RSV (Redes Sociais Virtuais) como uma ferramenta para o estudo de filosofia com o público de Ensino Médio. Esta possibilidade é construída a partir de uma relação com o conceito de Rizoma apresentado por Deleuze e Guattari (2000).

Pensar em RSV é refletir sobre mudanças comportamentais dos últimos vinte anos, pelo menos. É inegável que houve uma transformação sensível na forma como nos relacionamos com o ciberespaço, com as outras pessoas, e muito desta transformação passa necessariamente pelas conexões nas RSV. Para Recuero (2009, p. 15) "quando uma rede de computadores conecta uma rede de pessoas e organizações é uma rede social", e a conexão apresenta uma infinidade de possibilidades. As redes sociais em si não formam uma estrutura hierárquica verticalizada construída a partir de uma relação de poder, mas um espaço, em certo grau, livre, orientada por uma lógica associativa o que é demasiadamente intrigante. Partindo deste pressuposto é possível então, correlacionar o estudo de filosofia, RSV e o conceito de Rizoma. Além disso, sinto a inquietude de pensar a filosofia enquanto um componente curricular de ensino escolar. Segundo as Orientações curriculares para o Ensino Médio (BRASIL, 2006) a filosofia está para o estudante como um instrumento de criatividade, de curiosidade, de capacidade de pensar múltiplas alternativas. Para a proposta oficial é interessante pensar metodologias que associem sua dinâmica com a realidade circundante dos estudantes.

Diante destes pressupostos, previ na pesquisa, a realização de uma experimentação de atividade com os estudantes de Ensino Médio, na unidade curricular de filosofia mediada com o uso de RSV. Inicialmente a experimentação deveria acontecer em uma escola da rede pública estadual, mas ela não aconteceu. Diante da negativa, a experimentação aconteceu junto a estudantes de uma escola de ensino profissionalizante da mesma cidade. Neste artigo quero deter-me na reflexão sobre a não-experiência, projetada numa unidade de ensino na rede pública estadual catarinense.

\section{Metodologia}

A pesquisa teve como sustentação as características aproximativas do rizoma, apresentadas por Deleuze e Guattari (2000) na introdução do texto Mil Platôs: capita- 
lismo e esquizofrenia. 0 método rizomático ${ }^{8}$ guiou a experimentação e o utilizo para a análise. Ao abordar a filosofia e questões relativas a ela, os pensadores Deleuze e Guattari (2000), apresentam uma perspectiva diferenciada, provocando o pensar a partir de uma lógica não enrijecida. A proposta de um processo teórico-metodológico dado por meio do uso das características aproximativas do rizoma é uma via alternativa. Pensar "rizomaticamente" não é cair num relativismo em que tudo é possível, mas atentar-se às possibilidades de conexões. Na expressão de Recuero (2009), é pensar uma abordagem a partir dos "nós" que podem ser criados, "intermeio" das relações entre os atores sociais. Recorro à ideia de rizoma por conta do caos que é a timeline de uma RSV, um espaço que muda a cada momento ou uma filosofia da multiplicidade, como Aguiar (2010) chama. O rizoma, nesta pesquisa, desenvolve-se como um método processual, um impulso para uma "pesquisa-devir". Deleuze e Guattari (2010, p. 11) citam sua experiência como exemplo "escrevemos o anti-Édipo a dois. Como se cada um de nós era vários, já era muita gente (...) não somos mais nós mesmos. Cada um reconhecerá os seus. Fomos ajudados, aspirados, multiplicados". Um rizoma, segundo eles, não cessa de conectar-se, é múltiplo.

O rizoma é o método para pensar a experimentação; o fio da marionete que fundamenta teoricamente o texto e a multiplicidade que conduz a reflexão sobre todo este jogo. É a figura do ninho de ratos que Deleuze e Guattari (2010) apontam. Um misturarse um sobre os outros. Um sentido que se encontra na totalidade das ações.

A experimentação, como já mencionado, estava prevista para acontecer dentro das aulas de filosofia. A partir de um tema escolhido pelos estudantes, de acordo com as orientações curriculares de elemento de filosofia, desenvolveríamos atividades mediadas por uma ferramenta de formação de RSV. A mídia escolhida viria da indicação dos estudantes, de acordo com o perfil de uso da turma. Havia uma ideia, um eixo para seguir, os detalhes da construção nasceriam a partir do encontro com os estudantes.

\section{A experimentação}

A primeira tentativa de experiência havia sido pensada para acontecer numa escola da rede pública estadual de Santa Catarina. Antes de falar sobre ela quero apontar algumas características que dão cores ao desenho da escola para a qual o projeto fora pensando, melhor assim contextualizando. Os dados foram registrados em um diário de campo.

A escola oferece turmas de todo o ciclo da Educação Básica, atendendo aproximadamente oitocentos alunos, distribuídos em três turnos, provenientes do bairro no qual está situada e das comunidades circunvizinhas. O bairro, uma sede distrital de Blumenau, está distante vinte quilômetros do centro da cidade. Na arquitetura e nos hábitos ainda são mantidas características germânicas, herança dos primeiros imigrantes vindos da Alemanha. A estrutura econômica e a vida social giram em torno de uma

\footnotetext{
${ }^{8}$ Em Deleuze e Guattari não há um método nomeadamente rizomático como apresento aqui no texto. $O$ que diversos pesquisadores tratam como pistas para investigação é o chamado método cartográfico, conforme Passos; Kastrup e Escóssia (2009). Porém, opto pelos princípios aproximativos do rizoma e trato estes princípios como instrumentos metodológicos para a pesquisa, ouso, chama-lo de método rizomático, mesmo ciente que o rizoma, conforme Deleuze e Guattari (2000) descrevem está para a-método que propriamente para um método de pesquisa.
} 
grande "fábrica", que exerce influência sobre tudo o que acontece no bairro, mediante a geração de empregos diretos e indiretos, prestações de serviços e a vida cultural.

A primeira escola do bairro foi criada nos anos de 1920, a partir da necessidade de instrução básica aos moradores, sob iniciativa da comunidade, ensinando em língua alemã, porém os registros escritos não dão conta dos anos anteriores a 1940. Dos anos anteriores ao Governo de Getúlio Vargas (1930-1945) há somente relatos orais. Com as mudanças propostas pelo governo Vargas, a primeira escola passa a ter gerência estatal, apresentando inúmeras transformações, entre elas a obrigatoriedade do ensino em língua portuguesa e misteriosamente o sumiço de toda documentação da primeira inciativa. A escola, criada pela comunidade para suprir suas necessidades, por ingerência do Estado, tem implantada uma nova identidade, inaugurando um novo prédio e uma nova gestão no ano de 1954. Com as novas demandas e a expansão da educação no estado, a partir do ano de 1986 é ofertado o Ensino Médio, chamado na época de 20 Grau. Mesmo com estas mudanças a escola, fiel à sua história de raízes germânicas, manteve diversas das características iniciais, como a valorização dos costumes locais e a ligação com a "fábrica" local.

Da história, a experimentação. Os estudantes da turma convidada para participar da experimentação, eram do Segundo Ano do Ensino Médio. A turma era composta por trinta e quatro estudantes do turno noturno. No período diurno eles, ou já trabalhavam, ou procuravam emprego. A metade da turma residia no próprio bairro, enquanto que a outra metade vinha dos bairros vizinhos. Os que residem no bairro cursaram o Ensino Fundamental na própria escola, enquanto, os demais cursaram em outras instituições. Alguns destes somente acessavam à escola exclusivamente através do transporte escolar, pois há diversas localidades que não são atendidas pelo transporte coletivo público da cidade de Blumenau.

A experimentação foi pensada para acontecer no elemento curricular de filosofia, evidentemente. O professor titular é graduado em filosofia, efetivo na carreira, atua em mais escolas para completar sua carga horária. Analisei seu plano de ensino aprendizagem. Ele está construído pelo viés da história da filosofia. Para os alunos do Segundo Ano do Ensino Médio está previsto estudar os filósofos do período medieval aos filósofos modernos até o século XVII. A aula de filosofia é transformada em História da Filosofia. Tudo isto deve caber em duas horas aulas semanais.

O professor e a turma não utilizam o livro didático disponibilizado pelo Programa Nacional do Livro Didático. Justificam que não há exemplares suficientes para todos. A escola disponibiliza o livro Temas de filosofia, das autoras Maria Lúcia de Arruda Aranha e Maria Helena Pires Martins ${ }^{9}$. Ao invés do material didático disponibilizado, são utilizados esquemas e resumos distribuídos e organizados pelo professor, ora por fotocópias, ora via lousa. Além da sala de aula convencional, o professor ainda tem à disposição uma sala para projeção multimídia e o laboratório de informática (que está montado na biblioteca). O laboratório de informática está equipado com dez máquinas recebidas, em 2004, pelo Programa Nacional de Informática na Escola (Proinfo) ${ }^{10}$. Funcionam com sis-

\footnotetext{
${ }^{9}$ ARANHA, Maria Lúcia de Arruda. MARTINS, Maria Helena Pires. Temas de filosofia. 3. Ed. São Paulo: Moderna, 2005.

${ }^{10}$ Segundo Demarchi (2005, p. 49) O Proinfo “foi criado em 9 de abril de 1997 pelo Ministério da Educação por meio da Portaria n. 522, com a finalidade de possibilitar a implantação das novas Tecnologias de Informação e de Comunicação nas escolas públicas. As diretrizes do programa podem ser encontradas no documento Diretrizes do Programa Nacional de Informática na Educação, de julho de 1997. Funciona de
} 
tema operacional Linux Educacional 3.0 conectados à internet. A velocidade de conexão não foi divulgada pela escola, mas os estudantes, em conversas informais reclamam da pouca banda disponível no laboratório para as atividades escolares.

Esta experiência não deu certo, ela nem mesmo chegou a ser executada, apenas foi planejada entre as partes interessadas e combinada com a direção da escola. Inúmeros problemas dificultaram a tentativa de execução. Foi planejado que o professor titular de filosofia trabalharia um dos temas, em decisão conjunta com os estudantes, usando como instrumento auxiliar uma RSV, também escolhida pelos estudantes. Em conversa com os estudantes ficou acertado que o instrumento de formação de rede social seria 0 Facebook (www.facebook.com), entre as possibilidades apresentadas. Todos os estudantes optaram pelo Facebook porque a sala tinha um grupo já na ferramenta, formando uma rede social entre os estudantes, consequentemente todos mantinham perfis ativos na ferramenta. A experimentação deveria acontecer no quarto bimestre letivo de 2014, mas ela não aconteceu. Em conversa, o professor e a direção da escola apontaram como entrave o calendário escolar, a alteração constante da agenda de aulas, a indisponibilidade de uso do laboratório de informática e o firewall de acesso à Internet

\section{Discussão dos dados: a vitória do controle}

A experimentação foi planejada e combinada entre as partes para execução ao longo do segundo semestre letivo de 2014, entre agosto de novembro. Mesmo a escola trabalhando com um calendário de atividades prévias, estabelecidas e apresentadas no início do ano letivo, em fevereiro, alguns fatores causaram alterações e mudanças de atividades. Segundo a direção da escola, um dos entraves que "bagunçou" o andar do calendário foram os professores envolvidos no movimento da categoria que resultou em "estado de greve" durante o primeiro semestre do ano de 2014, entre abril e maio. Sem avaliar a validade ou não do movimento, ele resultou em vários dias de paralisações por conta de assembleias ou ações próprias. As paradas implicam em "calendário de reposição" o que trouxe alterações significativas no calendário previsto no início do ano letivo. Soma também eventos não planejados e "ordenados" pela Gerência de Estadual de Educação, além das constantes faltas de professores, por motivos não revelados pela escola, que trouxeram alterações e remanejamentos do quadro de aulas.

Os problemas não são dados isolados, mas estão entrelaçados, formando, também, um rizoma que permitem um olhar não fragmentado. Apesar de os pensarmos e analisarmos por partes, eles assim não o são. As diversas situações que trouxeram problemas para as atividades planejadas evidenciam problemas também na construção dos espaços de aula de outros componentes curriculares. A aula de filosofia, para a turma do Segundo Ano, conta com duas horas aulas semanais. O uso do laboratório de informática, e outros recursos multimídias para além da sala de aula devem ser reservados com antecedência. Quando acontece um remanejamento de aulas ou a troca de horários e alterações de programação, fatalmente o acesso aos recursos extras são afetados. Isso que diminui sensivelmente a possibilidade de uso de outros recursos nas atividades planejadas, para além do "tradicional".

forma descentralizada, em parceria com os governos estaduais, os quais possuem uma Coordenação Estadual de Tecnologias responsável pela criação dos Núcleos de Tecnologia Educacionais - NTE”. O programa pode ser acessado através do endereço http://portal.mec.gov.br/proinfo/proinfo. 
Com isto chegamos ao último problema, o firewall e o acesso à internet. O firewall instalado nos computadores impedia o acesso às ferramentas de RSV, não apenas ao Facebook, mas a outras, citadas pelos estudantes. O firewall que permite o acesso à internet possui, sem justificativa clara, um controle sobre o acesso de conteúdo. Este controle não é autorizado oficialmente pelo programa Proinfo, como também não há nenhuma linha no Projeto Político Pedagógico da escola que oriente ou normatize restrição. O profissional responsável pelo laboratório e a direção da escola não souberam responder sobre os motivos desse controle, apenas apresentaram suposições vagas. Não há profissional apto na escola, ou com conhecimento mínimo, para configurar ou caracterizar o firewall de acordo com as necessidades pedagógicas. Este problema não apareceu exclusivamente na realização da experimentação. Outros professores relataram a dificuldade encontrada em determinados acessos e a ausência de conhecimento técnico para alterar suas configurações. Diante de tudo isto, a experimentação, planejada, organizada e combinada previamente com os estudantes (atores), não aconteceu.

As dificuldades verificadas na escola requerem algumas reflexões,

[...] na sociedade de disciplina não se parava de recomeçar, enquanto que nas sociedades de controle nunca se termina nada, a empresa, a formação, o serviço, sendo os estados metaestáveis e coexistentes de uma mesma modulação, como que de um deformador universal (DELEUZE, 1992, p. 221).

O modo de funcionamento do modelo atual de sociedade mostra-se como um constante movimento, no qual nada é concluído, uma ilusão de caminhos, mas eles nunca chegam. Daí a justificativa de práticas como a "formação continuada". O que observei na escola foi a sensação de nunca haver conclusão. As atividades são planejadas, montadas, mas elas estão sempre sujeitas ao insucesso, por conta de inúmeros entraves impalpáveis, elas nunca concluem. Há sempre uma nova etapa de entraves a vencer, novas reformas esperadas, num paradoxo com a ideia de conclusão de cursos, por exemplo. São diversos os acontecimentos requerendo novas modulações, ações ondulatórias que funcionam num feixe contínuo (DELEUZE, 1992). Um movimento maquínico e não rizomático.

Um detalhe que me causou estranhamento foi o firewall de controle. Não é a existência dele em si, mas a ausência de um profissional apto para configurá-lo. Um mecanismo instituído, pensado como segurança aos olhares leigos, torna-se um muro, mais instransponível que o Muro de Berlim no auge da Guerra Fria.

Nas escolas, a expropriação dos saberes e a produção de novos saberes cria a organização hierárquica e, nela, um jeito de lidar com as funções, os graus, os tempos, os lugares, as pessoas, os saberes. Espaços que na sociedade de controle, ultrapassam os muros, porém, seguem disciplinando, recuperando, produzindo e controlando (CERVI, 2013, p. 30).

Cada máquina contém seus dispositivos e influencia nas formas de ação e interação humana. O computador, uma máquina aparente desatualizada que oferece um acesso precário a world wide web é controlada por um firewall para separar o que é lícito e o que é ilícito no acesso, segundo a burocracia hierárquica. Não se discute com os envolvidos, não se questiona o controle, apenas aceitação do que está dado no funcionamento da maquinaria. Isso dificulta a formação de nodos na escola entre docentes e 
discentes para construir coletivamente as possibilidades de acesso ao ciberespaço. 0 bloqueio foi instituído e está atuante, sem coletivos de uma educação menor (GALLO, 2003) para romper a exclusão do ciberespaço nos processos pedagógicos.

A crítica de Lévy (1999) às práticas sociais, sobre a maneira de duplicar no ciberespaço as mesmas formas de trabalho e de controle que já estão constituídas no espaço físico ajuda a compreender o controle de acesso imposto nessa escola. É contraditório estabelecer, através de um programa nacional, a garantia de acesso ao ciberespaço, como recurso didático e, ao mesmo tempo, condicioná-lo. Procuro um decalque para exemplificar a ação do cotidiano, não seria o mesmo que ofertar um pirulito a uma criança e retirá-lo antes dela poder lambuzar-se? Na atual Proposta Curricular, encontra-se a clara motivação às escolas para ir além, no uso das tecnologias, porque "os sujeitos deste tempo histórico interagem cada vez mais por meio delas" (SANTA CATARINA, 2014, p. 99). A aparente contradição entre a prática da escola com o bloqueio e a Proposta Curricular, encontra em Sgobin (2013, p. 253) uma motivação; ao comentar práticas-de-aula-que-se-querem-rizomar afirma que

a máquina-escola permite certos deslizamentos e mesmo pode aplaudi-los, desde que daí não surja ameaça séria ao sistema da máquina, nada que impeça seu movimento, dinamizado por engrenagens desenhadas conforme paradigmas vigentes.

É possível o acesso ao ciberespaço, desde que ele reproduza exatamente a mesma prática existente fora dele. $\mathrm{O}$ acesso a world wide web é limitado a um acesso que emula um livro didático. Os mecanismos de interação, construção coletiva, a formação de nodos, além de pesquisas em bases diversas, que fogem ao olhar de controle, não são permitidas. A instalação de tecnologias digitais na escola reproduz um espaço de confinamento, como se o mouse e uma tela interativa fossem extensão de um giz e uma lousa física. A inovação digital, diante dos mecanismos de controle não inova, apenas reproduz um estado de confinamento.

Diante da discussão sobre o espaço, físico e virtual, quero abrir um parêntese para além da experimentação e refletir sobre uma situação dada, relativa à estrutura da filosofia no contexto da escola, muitas vezes organizada como história da filosofia. Esse parêntesis requer uma conexão com o capítulo anterior, na seção que tratei do elemento curricular de filosofia. "A filosofia é teoria, visão crítica, trabalho do conceito, devendo ser preservada como tal e não como um somatório de ideias que o estudante deve decorar" (BRASIL, 2006, p. 35). Os Parâmetros Curriculares para o Ensino Médio, PCNs, apontam uma lista de temas de referência para o profissional docente de filosofia. São enumerados cerca de trinta temas e nenhum deles fala da história da filosofia como eixo. Na mesma linha, a BNCC, na versão preliminar, aponta que os componentes curriculares são apresentados "como experiências conectadas com a sua vida e problemas, escolares, políticos e existenciais" (BRASIL, 2015, p. 296). Quando a BNCC apresenta os componentes, o faz, a partir de temas e não apenas como ligação com uma linha histórica que pode comprometer a experiência significante que ela propõe. $E$ ainda, nos documentos estaduais encontramos uma listagem, na versão atualizada da Proposta Curricular de 1998 (SANTA CATARINA, 1999), de temas que seguem a mesma diretriz, mais tarde apresentada pelo PCN de filosofia. Uma lista com temas e não apenas a história da filosofia de maneira descontextualizada. Além do mais, "a história da filosofia exerce em filosofia uma função repressora” (DELEUZE, 1992, p. 14). 
Enfim, foram diversos fatores que impossibilitaram a primeira tentativa de experimentação. Experiências diferentes dos habituais que, em certo grau, querem-rizomar, conforme Sgobin (2013), andam num limite tênue entre a possibilidade e a máquinaescola. São conflitos que criam tensões e ruídos que, por vezes, podem gerar resultados; em outras, apenas desvelam questionamentos sobre as práticas, como em nosso caso, afinal "os anéis de uma serpente são ainda mais complicados que os buracos de uma toupeira" (DELEUZE, 1992, p. 226)

\section{Considerações finais e alguns entrelaçamentos}

A reflexão tem por objetivo de evidenciar que um não-acontecimento, na verdade é um dado, e que ele é, também, um acontecimento, um encontro de afetos para pensar deleuzo-guattarianamente. Mostra que diversas conexões são possíveis. Conectar-se com o inesperado, cartografando o novo cenário que se desenhou. Se a pesquisa inicial tinha um objetivo, ela precisou repensá-lo, mas o que foi desvelado no encontro da impossibilidade, foi uma pesquisa inesperada. Ainda assim, são conexões dotadas de uma ruptura assignificante. Trazendo outros nodos para o cenário. E estas ligações não podem ser desconsideradas, elas falam, são estratos de uma condição que está aí, proporcionando uma leitura de mundo, novos encontros e outras reflexões. Como a proposição deleuzo-guattariana permite um olhar a partir do rizoma, é possível estudar, caso contrário, seria uma produção arborescente, e não é este, o objetivo.

A escola, que território é este? Ela é marcada pela disciplina e pelo controle. É muito forte. O sentar, as filas, a posição das cadeiras, o lugar do professor, da direção, são apenas condições físicas que evidenciam um poder disciplinar ou do controle que atravessam locais e corpos. Além disto, há a força que age sobre datas, calendários, programações, forças invisíveis que impossibilitam a heterogeneidade. Aquilo que é previsto precisa acontecer. Arboresce o encontro entre estudantes e professores. Ele não é da ordem do afeto e dificulta o rizoma. Um território que não permite reterritorializações. Não escreve, a partir da não-experiência, mas a partir da dificuldade pensar outras experiencias. A ideia de uma grade curricular é forte, grade, aquilo que prende e impossibilita a outra-aprendizagem de acontecer. Um território, de raras reterritorializações.

As condições próprias de um tempo de viver as RSV, pode ser, em certo grau, um tempo de outras flexibilizações. Se pensarmos as RSV para além da captura que ela sofre do capital, seria tranquilo imaginar um transcender muros e paredes. As condições da mobilidade virtual, entretanto, são capturadas pelo poder disciplinar. O que leva ao enrijecimento de práticas no ensinar e aprender. Impossibilita o encontro e desafeta. Tudo é tão forte dentro de uma lógica do controle. Claro que as estruturas institucionais e da esfera pública precisam agir e viver de acordo com condições que as tornem de fato acessíveis a todos e que respeitem as condições que as fazem ser da esfera pública. Mas, os encontros precisam acontecer.

A reflexão ao se dirigir a experiência do não-acontecimento em si, precisa ter um cuidado reflexivo, porque houve outro-tipo de acontecimento. Houve um agenciamento do Estado sobre uma situação não prevista. $O$ agenciamento trouxe uma negativa para a experimentação acontecer tal qual foi planejada, mas ela aconteceu, doutra forma, como fatos, dados e sujeitos que estão para além da previsibilidade do pesquisador. 


\section{Referências}

AGUIAR, Lisiane Machado. As potencialidades do pensamento cartográfico: a cartografia de Deleuze e Guattari como método de pesquisa processual. In: Intercom - Sociedade Brasileira de Estudos Interdisciplinares da Comunicação, XXXIII Congresso Brasileiro de Ciências da Comunicação, 2010. Caxias do Sul, RS, 2 a 6 de setembro de 2010.

BRASIL. Base Nacional Comum Curricular: Consulta Pública. Proposta Preliminar. Segunda versão revista. Brasília: [S. n.], 2015.

. Ciências humanas e suas tecnologias: orientações curriculares para o Ensino Médio. Volume 3. Brasília: Ministério da Educação, Secretaria de Educação Básica, 2006. CERVI, Gicele Maria. Política na sociedade de controle. Rio de Janeiro: Achiamé, 2013. DELEUZE, Gilles. Post-Scriptum na sociedade de controle p. 219 - p. 226 in Conversações: 1972 - 1990. Rio de Janeiro: Editora 34, 1992.

DELEUZE, Gilles. GUATTARI, Félix. Mil platôs: capitalismo e esquizofrenia. Volume 1. 2a Reimpressão. Rio de Janeiro: Editora 34, 2000.

DEMARCHI, Marisa Elsa. Tecnologias na escola: o mito de Sísifo ou um salto na aprendizagem [dissertação]. Blumenau: Universidade Regional de Blumenau, FURB. Centro de Ciências da Educação, CCE. Programa de Pós-graduação em Educação, PPGE. Mestrado em Educação, 2005.

GALLO, Sílvio. Deleuze e a educação. Belo Horizonte: Autêntica, 2003.

LÉVY, Pierre. Cibercultura. São Paulo: Editora 34, 1999.

PASSOS, Eduardo; KASTRUP, Virgínina; ESCÓSSIA, Liliada da (org.). Pistas do método da cartografia: pesquisa-intervenção e produção de subjetividade. Porto Alegre: Sulina, 2009.

RECUERO, Raquel. Redes sociais na internet. Porto Alegre: Sulina, 2009.

SANTA CATARINA, Secretaria de Estado da Educação e do Desporto. Proposta Curricular de Santa Catarina: Educação Infantil, Ensino Fundamental e Médio: Disciplinas curriculares. Florianópolis: COGEN, 1998.

SANTA CATARINA. Governo do Estado de. Secretaria de Estado de Educação. Proposta Curricular de Santa Catarina: formação integral na Educação Básica. [S.I]: [S. n.], 2014.

SGOBIN, Alexsandro. Naus deleuzinas: em busca de práticas-de-aula-que-se-queremrizomar, p. 251-260. In.: GALLO, Sívio; NOVAES, Marcus; GUARIENTI, Laisa Balncy de Oliveira (orgs.). Conexões, Deleuze e política e resistência e... Petrópolis: De terus et alli; Campinas: ALB; Brasília: CAPES, 2013. 